\title{
DESIGN AND COMPARATIVE ANALYSIS OF MANUAL COMPACTORS FOR PET
}

\author{
Eng. Master Gabriel Cristian POROSCHIANU \\ PhD. Lecturer Georgeta HARAGA \\ "Politehnica" University of Bucharest
}

\begin{abstract}
As the world population continues to grow with every year so does our waste. Everyone knows that not all materials that are found in waste are recyclable, but we can focus on those that are. Therefore the main purpose of this paper is to show how easily we can use a manual compactor, especially if we innovate the classical concept by adding a heating system, thus focusing on recycling the millions of PET bottles that can be found in waste.
\end{abstract}

KEYWORDS: suitable environment, PET, electrical compactor, recycling, comparative analysis

\section{INTRODUCTION}

Nowadays, the environment appears to be a multidimensional reality that includes not only the natural environment but also the activities and creations of the people, which occupy a dual position, namely: the "components" of the environment and its "consumers / beneficiaries".

In this age of mass pollution of the Earth we need methods that can be integrated in the life of every human so we can diminish the pollution factor even if it is by a small percentage. The biggest concern in this age is the life of our planet, as numerous scientists have already predicted that the resources of Earth are almost at the end, thus we should focus on recycling everything that we can because it reduces the resources that we need to extract from Earth and at the same time we reduce the need to let recyclable resources self-degrade. Current design processes involve more complex products consisting of elements of design created by multiple teams, disciplines and suppliers using independent CAD systems. Even when mature $3 \mathrm{D}$ CAD technology is used, many companies fail to significantly reduce process losses, to improve product quality or product type [1].

This article is focused on recycling PET bottles using manual compactors designed for everyday home use. This helps us conserve space in our home so we can deposit more PET bottles and then give them away for recycling.

The life cycle for this material is a very short one but at the same time a long one, because the material used for one bottle can be reused several times. At this point there are many recycling deposits all over the country because everyone focuses on providing a place for people to drop their recyclable resources but no one focuses on a method to help them store the material in their home, so it can later be dropped at a recycling deposit. This article provides two manual compactors that can be used in any home to compress PET bottles. This process helps us to reduce the space for deposing.

PET (polyethylene terephthalate) bottles have been widely used as packaging materials for beverages, detergent and various consumer goods. Compounds such as polyethylene terephthalate have given plastic bottles several advantages, including toughness, energy savings and ease of production [2]. PET bottles are economical to make, safe to use and recyclable.

In this paper is put forward the principle of sustainable development for a social, economic and environmental policy, as well as its benefits in all three directions. PET bottles have a very large share of the world's use, due to their advantages: low cost, low specific weight, very high maneuverability, cheap manufacturing technology.

According to Research and Markets, the global production of plastic containers in 2014 was 50.1 Million Metric Tons (MMT) and is estimated to reach 67.9 MMT by 2020; a compound average growth rate of 5.2 percent and in terms of revenue, the market was worth \$273.15 billion in 2014 and will reach $\$ 388.35$ billion in 2020 at a growth rate of 6 percent [6].

Figures 1 and 2 show the Global production of PET and the Growth of plastic. 


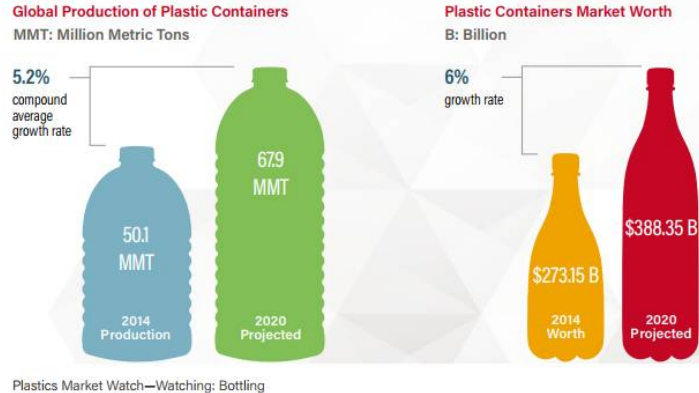

Fig. 1. Global production of PET [6]

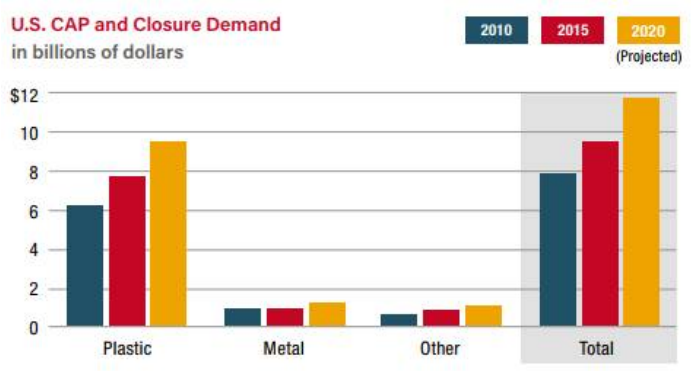

Fig. 2. Growth of plastic [6]

\section{THE BENEFITS AND}

DISADVANTAGES OF PET BOTTLES

PET bottles have many benefits and disadvantages such as [3]:

Benefits:

- higher resistance and stiffness than PBT (Polybutene terephthalate);

- heat deformation temperature higher than PBT;

- excellent electrical properties;

- wide range of operating temperatures, from $-60^{\circ} \mathrm{C}$ to $130^{\circ} \mathrm{C}$;

- low gas permeability, particularly carbon dioxide;

- recommended for transparent applications;

- good chemical resistance at room temperature;

- recommended for food and medicine;

- transparent to microwave radiation;

- recyclable.

\section{Disadvantages:}

- lower impact stiffness than PBT;

- slower mold formation than PBT;

- affected by boiling water;

- attacked by strong bases and alkanes;

- attacked at elevated temperatures $\left(>60^{\circ} \mathrm{C}\right)$ by ketones, aromatic and chlorinated hydrocarbons and weak acids and bases;

- low combustion behavior.

The processing and transport of PET bottles often involves difficulties and high costs.

PET is $100 \%$ recyclable (see figure 3 ). The recycling steps are: Collection, Sorting, Reclamation, Remanufacture, New Products and Purchase. It is important to buy products made from recycled materials in order to close the loop.
Maintaining the demand for recycled materials keeps the process moving and provides all the benefits of recycling. Make sure the products you buy contain post-consumer waste. The percentage of postconsumer waste is printed on the label. 1 ton of plastic is equivalent to 25,000 plastic bottles.
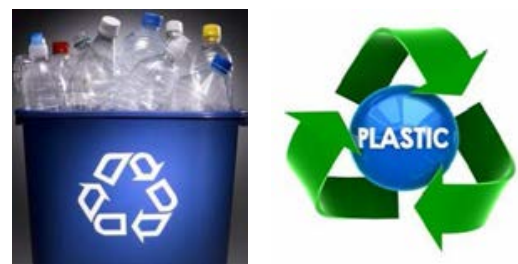

Fig. 3. Recycling plastic [2]

- A single recycled plastic bottle saves the energy required for keeping an electric light bulb working for six hours.

- 5 recycled PET bottles can be used to make an adult's fleece jacket [4].

\section{THE DESIGN OF THE ELECTRICAL COMPACTOR}

Compaction by manual deformation is not so very difficult. Given the rise in living standards, the need to have a PET compactor became necessary in every home, restaurant, school, institution, leisure place.

Using the compaction process for PET bottles offers several advantages:

- compacting PET bottles saves space and handling;

- increased density by compacting bottles rather

than baling;

- bottle caps popping off during compacting increases density.

The PET bottles can melt at a temperature between $80^{\circ} \mathrm{C}$ and $120^{\circ} \mathrm{C}$ as it varies depending on the treatment applied on the PET. The interior of this electrical compactor is filled with heating pipes that can reach a temperature of $120^{\circ} \mathrm{C}$ to ensure it will melt any PET bottle.

In order not to wait till the bottles melt by themselves, as it can take a while, there is also a compressing stick that helps with the entire process. This stick allows us to press on the bottles while they are heated which speeds up the compressing using manual pressing. The heat that is applied on the bottles softens them up so they can be pressed more easily and also to be more compacted. After this whole process, we wait till the material is cooled off and then we proceed to take out the interior recipient so we can deposit de compressed material or use it for ourselves as there are a lot of ideas on how we can use plastic at home to make our own home-crafts. It is very important to remove the label and the PET bottle cap before crushing a plastic bottle as these components are recycled separately [5]. Compacting plastic before collecting is very useful, because it significantly decreases the volume that it takes up, 
thus allowing for more plastic waste to be collected and transported. Additionally, transport time and costs are reduced, which helps collection companies and saves fuel. After compacting, bottles can be sold to a collecting centre, where they will be recycled.

The design of the electrical manual compactor PET proposed in this paper is made in a graphical program called Solidworks. SolidWorks is a CAD (computer aided drafting and design) software, currently owned and developed by Dessault Systemes SolidWorks Corporation. Its main destination is the $3 \mathrm{D}$ design software, and to be more specific, the mechanical design software. In comparison to other software, it is more user friendly, thus only a basic level of knowledge is required to use this software. I have used this software in order to create the main components of a design of a manual compactor for PET bottles, made of aluminum, because, compared to other similar software, SolidWorks puts an emphasis on modeling and not on learning how to operate the software. SolidWorks is a power graphical software which gives students and researchers the functionality and is ease-of-use so as to become productive almost immediately.

The processing and transport of PET bottles often involve difficulties and high costs. One of the major objectives of this paper is the need to recognize the importance of purchasing a PET bottle manual compactor in each household, in order to reduce transport and processing costs.

An electrical manual compactor for PET bottles saves transport costs in the sales of recyclable materials.

This electrical compactor is made of 4 components:

Component 1: A compressing stick which is used to manually compress the heated bottles as shown in figure 4 . This makes the compressing much easier as the bottles do not have the same resistance as they had when they were not heated.

Component 2: The interior of the compactor that is filled with heating pipes as it can be seen in figure 5 .

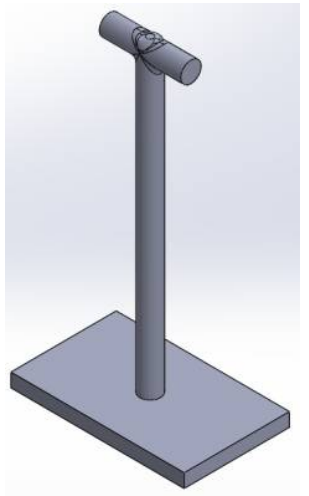

Fig. 4. Compressing stick

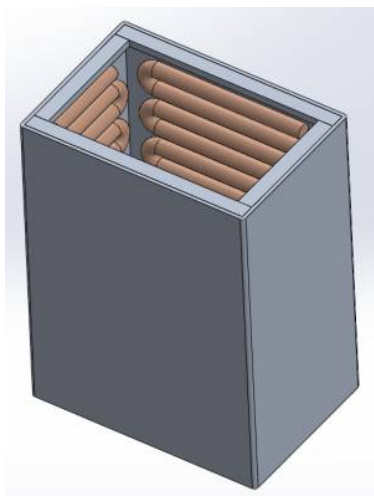

Fig. 5. The interior of the compactor
Component 3: An extractable interior recipient that is used to heat up the PET bottles and press them using the compressing stick as can be seen in figure 6 .

Component 4: Finally a socket cable that is used to power up the pipes so they can heat up and reduce the resistance from the bottles making them easier to press as shown in figure 7 .

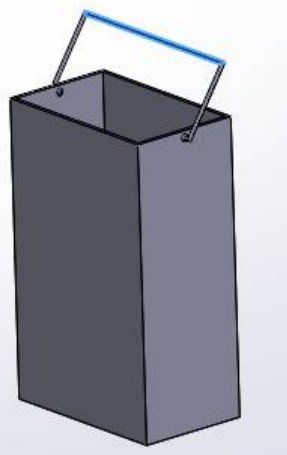

Fig. 6. Extractable interior recipient

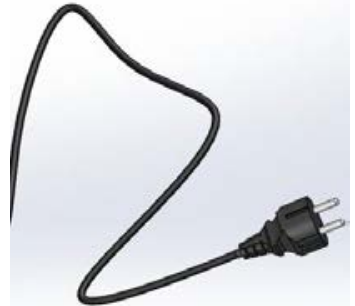

Fig. 7. Socket cable
Figures 8, 9 and 10 illustrate the steps required to compact PET bottles using the electrical compactor.

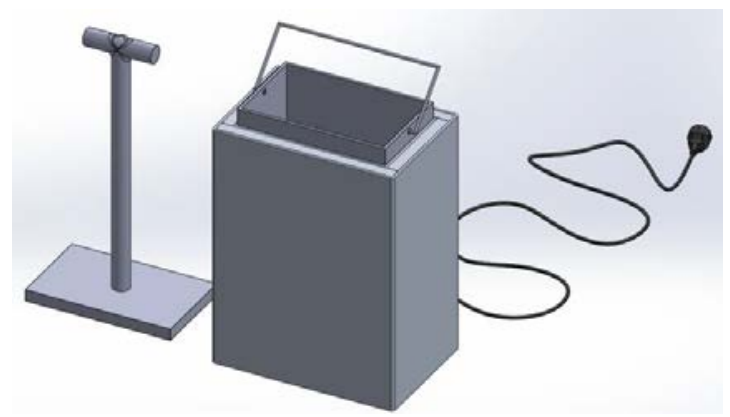

Fig. 8. Electrical compactor

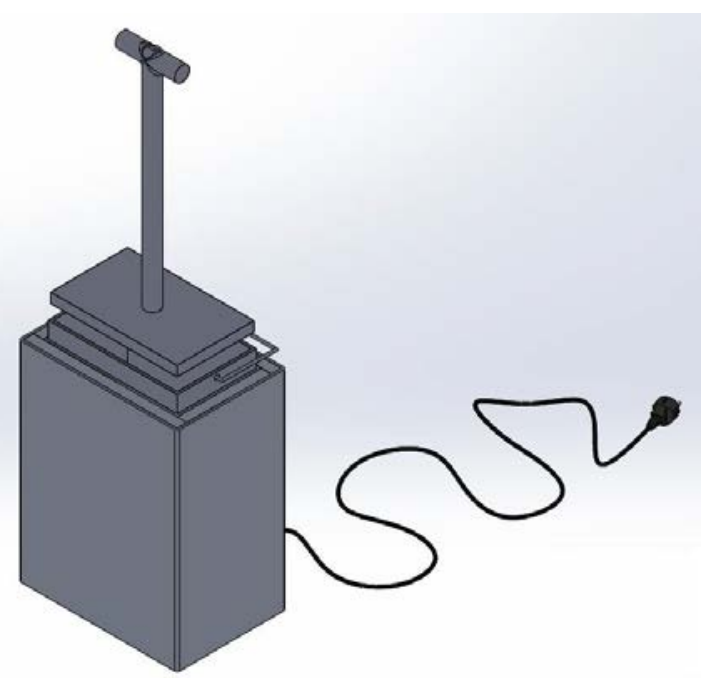

Fig. 9. Compressing using the compressing stick 


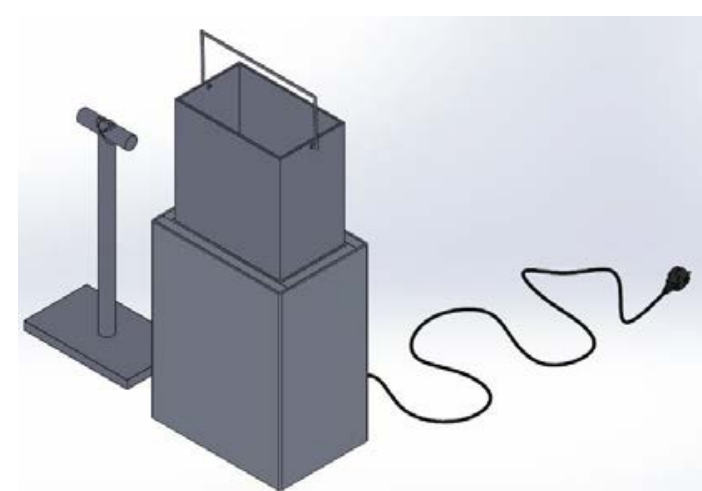

Fig. 10. Removing the extractable interior recipient

Figure 11 schematically illustrates the operating scheme of the electrical compactor.

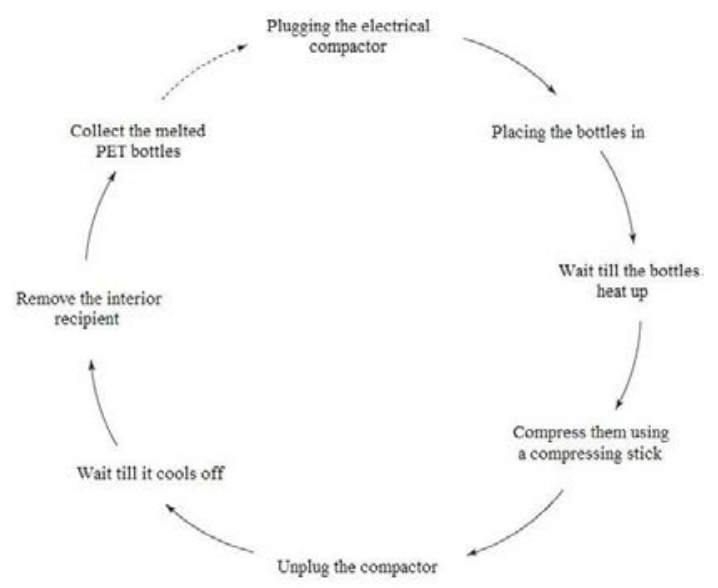

Fig. 11. Functioning mode of the electrical compactor

\section{COMPARATIVE ANALYSIS OF MANUAL COMPACTORS FOR PET}

As we will show in this next table there are quite a few strong points but also weak points on both compactors, as shown in table 1 .

Table 1

\begin{tabular}{|l|l|l|}
\hline \multicolumn{3}{|c|}{ Comparative analysis of manual compactors } \\
\hline points & $\begin{array}{l}\text { - can compact } \\
\text { multiple bottles at } \\
\text { the same time; } \\
\text { - can be used on } \\
\text { any type of bottle } \\
\text { - after the bottles } \\
\text { are melted the } \\
\text { material can be } \\
\text { reused in the } \\
\text { house }\end{array}$ & $\begin{array}{l}\text { - volume reduction } \\
\text { - easy to move } \\
\text { electricity } \\
\text { - can be used } \\
\text { anywhere }\end{array}$ \\
\hline
\end{tabular}

\begin{tabular}{|l|l|l|}
\hline Weak & - consumes & - can not be used on \\
Points & electricity; & any type of bottle; \\
& - you can burn & - it takes effort in \\
yourself is you are & compacting the \\
not careful; & bottles. \\
& it takes time to \\
heat up. & \\
\hline
\end{tabular}

The mechanical one can be used by any person and is risk free (there are no methods of causing an injury); while using the electrical compactor you can burn yourself if you are not careful. The biggest strong point for the electrical compactor would be that you can compress multiple bottles at the same time and their volume would decrease considerably compared to the mechanical one. Instead of repeating the cycle of compacting using the electrical compactor we can firstly use the mechanical one to quickly compress more bottles and reduce their total volume. This method saves up time, compresses the bottles to their fullest and we use less electricity for keeping the electrical compactor heated.

\section{CONCLUSIONS}

By collecting and recycling PET bottles we can greatly reduce the negative impact they have on the environment. The legislation in force supports this action, the result of this is the appearance of a considerable number of companies dealing with recycling and reusing this material.

In the context of assisting the population in accepting the idea of collecting and recycling PET products the waste bins will be made out of recycled aluminum. The planet's natural resources must be protected and handled in an appropriate manner and the only way we can achieve this is recycling.

Based on this paper we can determine that using heat during the process of compacting the PET bottles will reduce the force required during the mechanical pressing and it will also further decrease the volume of the bottles.

The electrical compactor compresses more quickly than the mechanical one but it also needs more care to avoid burns that can be caused by the heated parts of the compactor. The manual compactors are really practical and can come in handy for environmentally friendly households.

\section{REFERENCES}

[1] Goanţă A.M., "Digital development of products with NX9 for academical areas", ModTech2015, IOP Publishing, pp.1-6.

[2] http://education.seattlepi.com/importance-plastic-recycling5103.html

[3] http://www.mase-plastice.ro/dictionar/p/pet.html

[4] https://www.recycle-more.co.uk/household-zone/top-facts

[5] http://greenly.ro/deseuri/robopet-the-little-waste-compactor

[6]https://www.recyclingtoday.com/fileuploads/file/2017/03/Bottli ng\%20Plastics\%20Market\%20Watch\%20Report\%20digital.pdf 